\title{
The Study on Simulation of Parallel Circuit Resistance in Motor
}

\author{
Xu Run ${ }^{1 *}$, Zhiqiang Chen ${ }^{2}$ \\ ${ }^{1}$ Former Jhonsonelectric (HK) Co. Ltd, Sale and Technology Div. Shenzhen 518125 \\ ${ }^{2}$ Jhonsonelectric (HK) Co. Ltd, Sale and Technology Div. Shenzhen 518125
}

\author{
DOI: $10.36348 /$ sjet.2020.v05i11.014 $\quad$ | Received: 10.11 .2020 | Accepted: 27.11 .2020 | Published: 25.11 .2020
}

*Corresponding author: $\mathrm{Xu}$ Run

\section{Abstract}

The stall phenomenon which happens in loaded motor is unqualification in application. Meanwhile it may measure the maximum property of motor in manufacture. So the phenomenon of multiple circuit is analyzed to find a simulation of electrical state to predict the maximum currency and torque which is a necessary method to be proceeded up to now before design. We find that the simulation fits well to the reference. The conditions of multiple circuit with $t=6 \mathrm{~s}, \mathrm{U}=12 \mathrm{~V}$ result in the biggest stall force according to rotation to change time and voltage. Then it is $t=8 \mathrm{~s}, \mathrm{U}=10 \mathrm{~V} ; \mathrm{t}=10 \mathrm{~s}, \mathrm{U}=8 \mathrm{~V}$ and $\mathrm{t}=12 \mathrm{~s}, \mathrm{U}=6 \mathrm{~V}$ in turns. As for torque it is $\mathrm{t}=6 \mathrm{~s}, \mathrm{U}=12 \mathrm{~V} ; \mathrm{t}=8 \mathrm{~s}, \mathrm{U}=10 \mathrm{~V} ; \mathrm{t}=6 \mathrm{~s}, \mathrm{U}=12 \mathrm{~V}$ and $\mathrm{t}=12 \mathrm{~s}, \mathrm{U}=6 \mathrm{~V}$ in truns. When the voltage decreases resistance declines the rotation will decline in the end.

Keywords: Simulation, parallel, stalling, rotation, resistance, motor.

Copyright (C) 2020 The Author(s): This is an open-access article distributed under the terms of the Creative Commons Attribution 4.0 International License (CC BY-NC 4.0) which permits unrestricted use, distribution, and reproduction in any medium for non-commercial use provided the original author and source are credited.

\section{INTRODUCTION}

Motor slow rotation and stall is a severe quality issue in manufacture so it is needed that we shall pay more attention to it under multiple circuit. When the temperature is high, the free electrons collide big with the atoms that vibrate $[1,2]$. In virtual welding, its resistance increases and the current decreases, so its rotation decreases at the same voltage. Variable clearance of rotor and bearing will cause periodic load fluctuation, which will cause voltage decrease, and the rotation will be slow or even stop. After using the motor for a period of time in series circuit and multiple circuit, the friction of the rotor causes fluctuation, so we need to pay attention to the motor wear under the action of adjustable resistance in multiple circuit will also cause stall which is investigated in this paper after done in last paper about series circuit resistance [3]. In the machine tool if the long time rotation produces bearing wear need to replace it immediately in order to ensure the long time use of the rotating shaft. The above is the status of stall motor [4]. So we regulate the resistance in order to change current for observing the stall torque. But it is found that the resistance can't cause big torque or stall torque due to its weakness. This is a conclusion from this study. But the rotation is available to present a certain torque even stall torque because they are high enough. This is a new finding in this paper. So it is thought that the further research will be proceeded on this resistance later. To promote resistance and current is a way to approach the stall torque.

Modeling in Multiple Resistance and Discussion According to energy $\mathrm{W}$ in multiple circuit defining gains

$d W=F d s$

Due to $\frac{d W}{d s}=F$

So $P=F v$

Here $\mathrm{F}$ is force; $\mathrm{s}$ is distance.

From electric power $\mathrm{P}$ and energy conservation law in terms of Figure-1 which is circuit simulation to estimate the stall status in multiple circuit it gains, here $\mathrm{R}_{1}$ is adjustable resistance; $\mathrm{R}_{2}$ is motor resistance.

$$
\begin{gathered}
P=I U=I^{2} R \ldots \ldots \ldots \\
\text { and } P t=\frac{1}{2} m v^{2} \ldots \ldots \ldots \\
\text { Suppose } v=\frac{v_{\text {shaft }} d_{1} k}{d_{0}}
\end{gathered}
$$


Xu Run \& Zhiqiang Chen; Saudi J Eng Technol, Nov, 2020; 5(11): 480-482

Here $\mathrm{k}$ is $0.607 \sim 0.5 ; \mathrm{d}_{1}$ is armature diameter; $\mathrm{d}_{0}$ is shaft diameter; $\mathrm{v}_{\text {shaft }}$ is shaft speed; $\mathrm{v}$ is armature speed. From above two equations it gains the velocity

$v^{2}=\frac{2 P t}{m}$

Replace (2) with (1) it gains

$d v=d \sqrt{\frac{2 I^{2} R t}{m}}$

Here $\mathrm{t}$ is time; $\mathrm{R}$ is resistance; $\mathrm{m}$ is mass of rotor.

From equation (1) and (2) gains

$T=F r$ and $F=\frac{P}{v}$

Due to velocity $v=r \omega$

Gains $v=\frac{\pi d n}{60}$

from (3) (9) and (10) gains the torque $\mathrm{T}$ of main shaft equation is

$T=9.55 \frac{P}{n}$

Replace above with (1) It gains the simplicity one as below

$d T=9.55 \frac{I^{2} d R}{n}$

Here $\mathrm{n}$ is rotation.

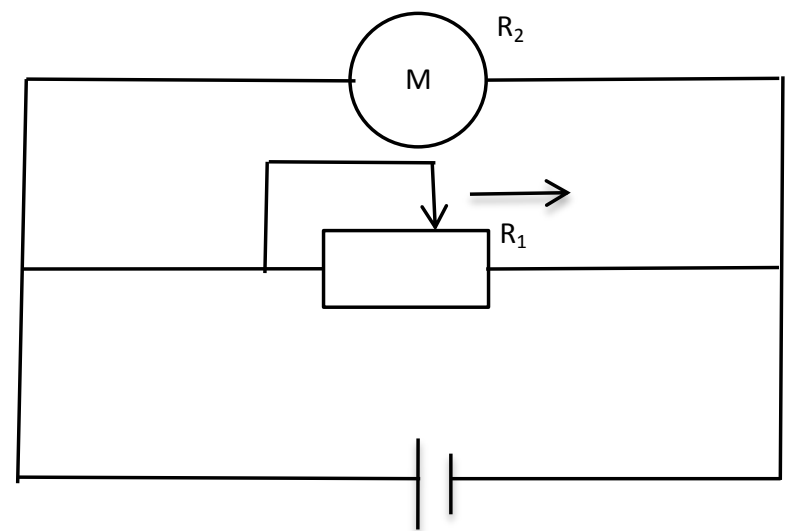

Fig-1: Circuit simulation under motor and variable resistance $R$ in parallel

\section{DISCUSSIONS}

In company the motor electrical property about the stall currency is proceeded by experiment method. If they are predicted the much save will be gained. So in this paper we build the equation modeling to analyze it with different conditions on parallel.
As shown in Figure-2 the result fits well with the reference practice. Two conditions are used to model the situation of practice which is stall time and voltage. Here the rotation is used to evaluate. Meantime the $6 \sim 12 \mathrm{~s}$ (second) and $12 \sim 6 \mathrm{~V}$ is adopted to do equation. It is observed that rotation is accession to 900rpm under $\mathrm{t}=12 \mathrm{~s}, \mathrm{U}=6 \mathrm{~V}$ and $1800 \mathrm{rpm}$ under $\mathrm{t}=6 \mathrm{~s}, \mathrm{U}=12 \mathrm{~V}$. At last $1800 \mathrm{rpm}$ is acquired under $\mathrm{t}=8 \mathrm{~s}$, $\mathrm{U}=10 \mathrm{~V}$. Moreover 950rpm is gained under $\mathrm{t}=6 \mathrm{~s}, \mathrm{U}=12 \mathrm{~V}$ at $400 \Omega$. The highest rotation happens in $\mathrm{t}=8 \mathrm{~s}, \mathrm{U}=10 \mathrm{~V}$ meantime the lowest one does in $\mathrm{t}=12 \mathrm{~s}, \mathrm{U}=6 \mathrm{~V}$. The highest is in $\mathrm{t}=8 \mathrm{~s}, \mathrm{U}=10 \mathrm{~V}$ which results in the lowest torque to resist stall. The curve will decrease steeply after $150 \Omega, 200 \Omega$ and $400 \Omega$. It expresses that the low rotation happens after these resistance.

Poor voltage design in the circuit or transformer parts damage will cause the motor slow down and other phenomena. So in the design or use to ensure that the voltage is large enough. If the transformer is not used properly, the voltage will be reduced or even no voltage. These will cause the motor revolution to slow down or even stop so we need to pay attention to their voltage changes. If the voltage goes up and the current goes up the motor burns out and it's dangerous so we have to be careful about whether the voltage goes up or down. The voltage in the circuit we designed should not be too small or the rated voltage of the motor should be consistent with the design voltage. If the two do not match, the motor will burn off or stop running, be sure to attract the attention of the relevant engineer. The transformer must be precisely adjusted before it can be used for measuring and using motors. When the PLC design is electrical components damage caused by short circuit will cause the voltage increased need to pay attention to. Circuit design needs to protect the function of the motor, but also should be concerned about circuit short circuit and other voltage or current caused by excessive motor fault. Some circuit design is a functional role in order to make the motor to achieve the required a certain functions such as printer quickly followed suit, normal feed and fast return to demand, so the current board PLC(Programmable logic controller), PWM(Pulse width modulation), servo motor in the control of motor cycle with a certain load are prone to fatigue, leading to print qualities such as tilt up and down and not docking phenomenon. These are the side effects of motor dynamics after long-term use, belong to the motor life has reached the limit, out of service. If the equipment is new, replace the motor, but the factory needs to provide the motor. I bought a Samsung tape recorder in South Korea and after a while it suddenly stopped working. I went to the exclusive maintenance point to check that the motor burned out, a week later only to get the replacement of the motor recorder from then on no major problems. This is due to the motor that drives the tape under a certain load. In addition, the motor that drives the plasma arc furnace in the laboratory to control the speed of the circular shaft also broke down during the cycle of use, which was also 
caused by excessive load. The motor is a precision product made in Japan, but it also fails under the high load. Because it cannot be bought, it has to change a spare one to guarantee its use function. These are mechanical and electrical products under high voltage motor failure. So do not only seek accuracy and harm the load of this requirement, to strengthen the basic design of the motor, in the premise of ensuring the service life of the guarantee of precision. It is necessary to enhance the load and fatigue test of the motor sample, so as not to cause the shutdown within the specified period, tarnish the company's image and reduce the order quantity.

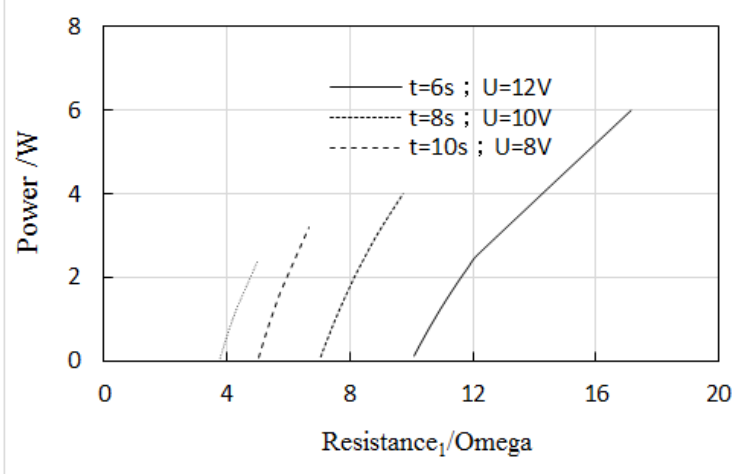

Fig-2: Relations of simulation power and resistance 1 under a certain time and $U$

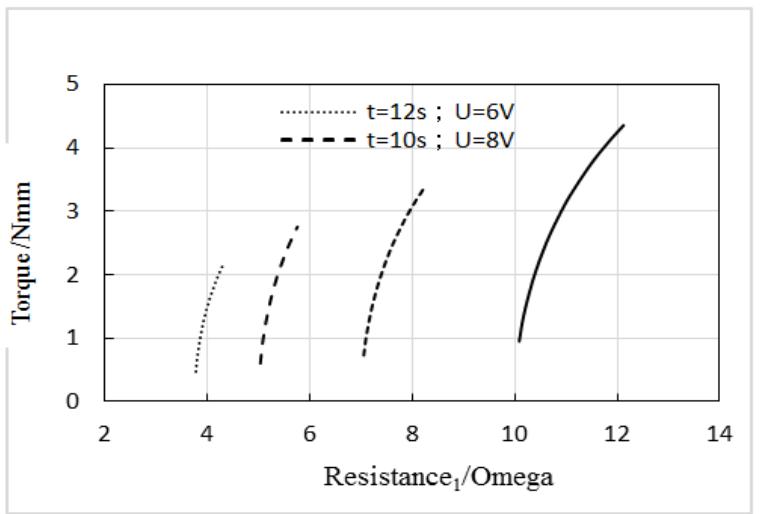

Fig-3: Relations of simulation torque and resistance under a certain $t$ and $U$

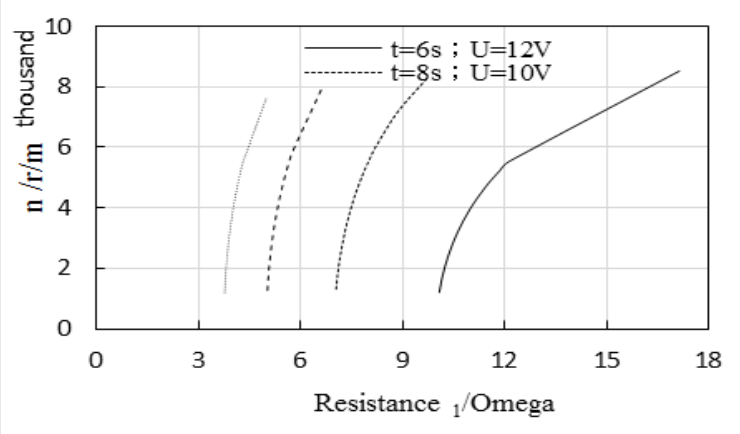

Fig-4: Relations of simulation rotation and resistance 1 under a certain time and $U$

As shown in Figure-3 the torque will decrease with increasing resistance meantime it will become $4 \mathrm{Nmm}, 3 \mathrm{Nmm}, 2.5 \mathrm{Nmm}$ and $2 \mathrm{Nmm}$ under the different time and voltage of the above turn at $30 \Omega$. At the $t=12 \mathrm{~s}$ and $\mathrm{U}=6 \mathrm{~V}$ the torque will decrease at the utmost. Due to simulating stall it is limited by variable $\mathrm{R}$ value, so the rotation reflects this status optimum. According to rotation the resistant force is judged in this study.

As seen in Figure-4 the rotation of motor will incline when the resistance inclines. It is due to multiple circuit resistance which is in opposition to series connection. The steeper curve will be gained that means a little increasing resistance will cause rotation increasing rapidly. The voltage is the bigger the resistance will bigger too. Meantime the sluggish curve will be observed in this study.

\section{Conclusions}

The rotation can be presented a stall torque which fit to well it. It can be controlled through resistance. But the torque is too small in terms of theoretical calculation because of their weakness role. So if we promote the torque value it shall be controlled that current and voltage is main factor for further research. The conditions of $\mathrm{t}=6 \mathrm{~s}, \mathrm{U}=12 \mathrm{~V}$ result in the biggest stall force according to rotation to change time and voltage. Then it is $\mathrm{t}=8 \mathrm{~s}, \mathrm{U}=10 \mathrm{~V} ; \mathrm{t}=10 \mathrm{~s}, \mathrm{U}=8 \mathrm{~V}$ and $\mathrm{t}=12 \mathrm{~s}, \mathrm{U}=6 \mathrm{~V}$ in turns. As for torque it is $\mathrm{t}=6 \mathrm{~s}, \mathrm{U}=12 \mathrm{~V}$; $\mathrm{t}=8 \mathrm{~s}, \mathrm{U}=10 \mathrm{~V} ; \mathrm{t}=10 \mathrm{~s}, \mathrm{U}=12 \mathrm{~V}$ and $\mathrm{t}=12 \mathrm{~s}, \mathrm{U}=6 \mathrm{~V}$ in truns. With decreasing voltage the resistance will become little and rotation will decline in the end.

\section{REFERENCES}

1. Qin, Z. (2015). Electrics. Advanced Education Publisher, 264.

2. Fitzgerald, A. E. (2003). Electric Machinery. 101.

3. Run, X., \& Zhiqing, C. (2020). The Study on Simulation of Resistance in Stall Motor, Journal of Electronic \& Information Systems, 2(1):18-20.

4. Run, X., \& Zhiqing, C. (2020). Technological Analysis on Motor Stall and its Perspective, Electrical Science \& Engineering, 2(1):26-29. 